\title{
Transnational by Default: Online Child Sexual Abuse Respects No Borders
}

\author{
Sabine K. Witting \\ Guest lecturer at eLaw - Center for Law and Digital Technologies, University \\ Leiden, Leiden, The Netherlands \\ sabine.witting@gmx.de
}

\begin{abstract}
Combatting child sexual abuse on the internet requires a high level of harmonisation of both substantive and procedural laws, as online child sexual abuse is transnational by default: while the transnational nature of child sexual abuse material used to be the exception before the advent of the internet, it is now the rule. In order to prosecute and investigate online child sexual abuse across country borders, states rely heavily on extraterritorial jurisdiction clauses as well as informal and formal law enforcement collaboration channels. This paper analyses existing channels in the opsc, Budapest Convention and Lanzarote Convention, particularly against the background of the recently published CRC Committee Guidelines regarding the implementation of the Optional Protocol to the Convention on the Rights of the Child on the sale of children, child prostitution and child pornography (CRC/C/156), and provides for concrete guidance on how to ensure that the best interests of the child in the prosecution and investigation of transnational crimes such as online child sexual abuse is the primary consideration.
\end{abstract}

\section{Keywords}

online child sexual abuse - child sexual abuse material - OPSC - CRC Committee violence against children - jurisdiction - mutual legal assistance - extradition

\section{Case study}

Anna is a seven-year-old girl, who was born and resides in the Netherlands as a Dutch national together with her father, a German national. On 
a family holiday to Canada, her father, together with a Canadian family friend, takes a video of them jointly sexually abusing Anna and uploads this video to an open-source website. The website is hosted on an American server. Ever since, the video has been downloaded thousands of times. Law Enforcement in South Africa find the material on a computer they seize from a suspected child sex offender who possessed the material for private use only and manage to identify Anna. Anna's father, the Canadian family friend and the South African client are arrested.

The above case study is fictional, but children worldwide share Anna's destiny. While sexual abuse used to be restricted to the homes and communities the children live in, children are now at an additional risk of online violence, perpetrated both by people known and unknown to them. The CRC Committee notes in its new General Comment No. 25 on children's rights in relation to the digital environment, which was adopted on 2 March 2021, that children might be targeted by families or friends for digitally facilitated forms of violence (CRC Committee, CRC/C/CG/25). At the same time, offenders use the realm of the internet to befriend and groom children they do not know in real life to sexually abuse them both online and offline (UNICEF, 2017).

Combatting child sexual abuse on the internet requires a high level of harmonisation of both substantive and procedural laws (CRC Committee, $\mathrm{CRC} / \mathrm{C} / \mathrm{GC} / 25$ ), as online child sexual abuse is transnational by default: while the transnational nature of child sexual abuse material used to be the exception before the advent of the internet, it is now the rule. Considering this transnational and cross-border nature of online child sexual abuse, the CRC Committee stresses the importance of strong international and regional cooperation mechanisms (CRC Committee, CRC/C/CG/25). In order to follow this shift in offending behaviour and avoid the creation of "safe havens", countries require harmonised legal mechanisms to facilitate the investigation and prosecution of offences beyond their territorial borders (UNODC, 2013). As the harmonisation of substantive laws is hampered by varying constitutional, moral and ethical concerns on a national level, ${ }^{1}$ procedural law in many cases equally fails to provide for harmonised standards in adjudicating and investigating cybercrime (Miquelon-Weisman, 2005). Traditionally, the power to investigate

1 For a comprehensive discussion on emerging forms of online child sexual abuse, such as virtual child sexual abuse material and self-generated imagery, see Sabine K. Witting, "The 'Greyscale' of 'Child Pornography': Of Mangas, Avatars and School Girls: Part 1', Computer and Telecommunications Law Review 2018 (3); Sabine K. Witting, "The 'Greyscale' of 'Child Pornography': Of Mangas, Avatars and School Girls: Part 2", Computer and Telecommunications Law Review 2018 (4); Sabine K. Witting, "Regulating bodies: the moral panic of child sexuality in the digital era", Critical Quarterly for Legislation and Law 2019 (1). 
and prosecute offences, including the claiming of jurisdiction, was tied to the territory of each state. This territoriality principle is founded in the protection of state sovereignty, a core value protected under international customary law (Osula (b), 2015; Ryngaert, 2015; UNODC, 2013). If a state intends to investigate an offence on the territory of another state, special bilateral mechanisms are required, in order to ensure that sovereignty of the other state is not violated (UNODC, 2013).

In the realm of the internet, these principles are overtly complicated by the mere architecture of the cyberspace. As the internet know no borders, crimes are naturally committed across numerous jurisdictions. Perpetrators can easily hide their identities, and the traces and evidence they leave (if any) is highly volatile and easily removed, altered or hidden (Broadhurst, 2006; Oerlemans, 2017). Determining whether an offence was committed in- or outside a state's territory is increasingly difficult. In Anna's case: was the online child sexual abuse offence committed on the territory of Canada, because the material was uploaded there? Or in the US, which was the location of the server onto which the material was uploaded? Regarding investigation of the offences, are Dutch law enforcement authorities allowed to conduct open source investigation on the American server, or is this considered to be an extraterritorial activity, which potentially violates the sovereignty of the US and hence requires US consent? Given the volatile nature of digital evidence, which are the channels the Netherlands could leverage to obtain such evidence in a quick manner, while obeying Dutch law of evidence rules so as to ensure admissibility of obtained evidence in Dutch courts? In summary, the key questions which need to be answered are:

1) Does the country have jurisdiction? What happens if more than one country claims jurisdiction?

2) If a country requires investigation support from another country, how can such collaboration be facilitated in a timely and efficient manner? If the country needs to extradite, how can this be accomplished?

3) How can transnational law enforcement mechanisms take the specific considerations of child victims into account?

In order to facilitate such transnational law enforcement collaboration, states largely depend on both formal and informal collaboration channels. While informal collaboration mechanisms are based on transnational police networks or peer-to-peer police support (UNODC, 2013), the formal collaboration channels are rooted in bi- and multi-lateral mutual legal assistance and extradition agreements, which play a key role to ensure evidence can be obtained outside a state's territory (UNODC, 2012). The most important international instruments to facilitate such collaboration in the area of online child sexual 
abuse are the UN Convention on the Rights of the Child's Optional Protocol on the sale of children, child prostitution and child pornography (hereafter: OPSC), the Council of Europe Convention on Cybercrime (hereafter: Budapest Convention) and the Council of Europe Convention on Protection of Children against Sexual Exploitation and Sexual Abuse (hereafter: Lanzarote Convention). All three Conventions not only provide guidance to states on the regulation of online child sexual abuse, ${ }^{2}$ but also include provisions on jurisdiction, mutual legal assistance, extradition and other transnational law enforcement mechanisms. This shows the importance of specific transnational collaboration mechanisms for effectively combatting online child sexual abuse worldwide.

It is against this background that this article aims to analyse the transnational law enforcement mechanisms contained in the above-mentioned international instruments. Anna's case will hereby assist in understanding the complexities of jurisdiction, mutual legal assistance and extradition in cases of online child sexual abuse. The opsc, Budapest Convention and Lanzarote Convention have been chosen for this analysis, as the OPSC is the most ratified and the Lanzarote Convention the most recent child protection convention with a specific focus on "child pornography", while the Budapest Convention is the most ratified international cybercrime treaty. ${ }^{3}$ Further, this article aims to identify specific considerations in transnational law enforcement with regards to cases of online child sexual abuse and provide for recommendations how a child-centered approach to transnational law enforcement can contribute to ensure the best interests of the online child sexual abuse victim are the paramount consideration throughout the formal justice process.

Before diving into the jurisdiction clauses in the OPSC, Budapest Convention and Lanzarote Convention, this section will give a brief introduction to the concept of jurisdiction. The analyses of the treaty-specific jurisdiction clauses

2 For a comparative analysis of the child sexual abuse material offences in the opsc, Budapest Convention and Lanzarote Convention, see UNICEF, Regulation of Child Online Sexual Abuse. Legal Analysis of International Law \& Comparative Legal Analysis (Windhoek, 2016).

3 The 2000 United Nations Convention against Transnational Organized Crime only covers transnational offences committed by an organised criminal group (Arts. 2, 3). As online child sexual abuse offences can, but do not always, form part of organised crime, this Convention will be excluded. 
will be followed by a discussion around determination of intra- and extraterritoriality, and the dissolution of jurisdiction conflicts applying the "rule of reason". While this introduction seems to be far away from the "core business" of children's rights advocates, it is important to understand the complex dynamics of jurisdiction to make meaningful contributions on how jurisdiction regimes can be strengthened from a child rights perspective.

\subsection{Concept of Jurisdiction}

In order to understand the concept of jurisdiction, it is crucial to point out the interlinkages with the principle of state sovereignty, which is protected under customary international law (UNODC, 2013). The principle of sovereignty states that states shall not 'interfere in any form or for any reason whatsoever in the internal and external affairs of other States' (see Art. 1 of the UN Declaration on the Inadmissibility of Intervention in the Domestic Affairs of States, A/RES/36/103, 9 December 1981). The principle of sovereignty is expressed in various forms of jurisdiction, i.e. jurisdiction to prescribe, jurisdiction to adjudicate and jurisdiction to enforce (Osula (b), 2015; Ryngaert, 2015). Jurisdiction to prescribe covers a state's power to regulate the actions and activities of certain people by law, policy or administrative act, while the jurisdiction to adjudicate means a state's power to submit certain persons or entities to its courts. Lastly, the jurisdiction to enforce entails a state's power to enforce its laws through means of executive or administrative acts, i.e. compel compliance or punish non-compliance (Brenner/Koops, 2004; Osula (b), 2015; Svantesson/Gerry, 2015). In conclusion, the power to regulate, adjudicate and enforce is at the core of a state's 'internal affair'.

As sovereignty in the context of the Westphalian bent of the international legal order is derived from the notion of territorially separate nation states, the predominant factor to determine the reach of a state's sovereignty is its territory (Kolossa, 2019; Osula (b), 2015; Ryngaert, 2015). Therefore, jurisdiction is generally based on two principles: territoriality and extra-territoriality. As extra-territorial jurisdiction potentially violates the sovereignty of another state, the default rule is that extra-territorial jurisdiction can only be exercised if there is a specific permissive rule (Kolossa, 2019). There are various approaches on how to establish extra-territorial jurisdiction. The most important component is the link to the asserting state, which can be established in different ways. For example, an asserting state justifies a link to their home country based on the nationality of either the offender ("active personality principle") or the victim ("passive personality principle"), the state's interest to protect its country from a national threat (" protective principle") or a state's interest to rely on universal jurisdiction for a small number of " international 
crimes" (Gillespie, 2012; Ryngaert, 2015; for an in-depth analysis of the various forms of jurisdictions, see Ireland-Piper, 2015). As online child sexual abuse is not generally recognised as international crime and does not pose a national threat to states (Gillespie, 2011), this article will only focus on the active and passive personality principle.

Even though the range of a state's extraterritorial jurisdiction is ultimately determined at a national level, international conventions such as the opsc, Budapest Convention and Lanzarote Convention have provided guidance on the range of jurisdiction clauses with the aim to protect (child) victims and to prevent impunity. Further, international conventions assist in establishing a harmonised approach between state sovereignty on the one hand, and the states' interests to investigate and prosecute offences which affect them on the other hand.

The next section will therefore provide for an overview of the range of (extra-) territorial jurisdiction clauses in above mentioned international conventions.

\subsection{Jurisdiction Clauses in Relevant International Conventions}

This section will provide an overview of the nature and range of jurisdiction clauses in the OPSC, Budapest Convention and Lanzarote Convention.

Article 4 OPSC provides for a territorial and extraterritorial jurisdiction provision in cases of Article, 3 (1) OPSC offences, i.e. sale of children, child prostitution and child pornography.

\subsection{Wording and Interpretation of Article 4 OPSC}

Article 4 (1) OPSC states that:

each State Party shall take such measures as may be necessary to establish its jurisdiction over the offences referred to in Article 3, paragraph 1, when the offences are committed in its territory or on board a ship or aircraft registered in that State.

Article 4 (1) OPSC therefore establishes territorial jurisdiction, including ships or aircrafts registered in the concerned state. The term "shall" shows that this is an obligatory clause for all state parties. 
Article 4 (2) OPSC extends the range of jurisdiction to offences committed outside the state's territory. The clause states:

Each State Party may take such measures as may be necessary to establish its jurisdiction over the offences referred to in Article 3, paragraph 1, in the following cases:

(a) When the alleged offender is a national of that State or a person who has his habitual residence in its territory;

(b) When the victim is a national of that State.

The term "may" indicates that this extension to extra-territorial jurisdiction cases is merely optional for state parties. The extraterritorial jurisdiction clause encompasses both the active and passive personality principle. Additionally, it extends the active personality principle to persons who merely have their habitual residence in the state party, without being citizens. This extension is somewhat questionable, as a resident does not profit from the benefits and protections extended to citizens by their home state. While it is justifiable that a resident needs to obey the laws and rules of his or her host state while being on its territory, it seems less justifiable that the same applies if he or she is in a third country (arguing that the assertion of jurisdiction over residents is in violation of international law, Ireland-Piper, 2012). Applying this to the above case study, this would mean that the Netherlands could claim jurisdiction over Anna's father, even though he is a German national and committed the offence while being in Canada, merely because he permanently resides in the Netherlands. Even though this construction evidently aims to avoid any jurisdictional loopholes, particularly in the case of travelling sex offenders, it bears the risk that countries artificially extend their jurisdiction and impose their laws on citizens of other countries.

Article 4 (3) OPSC states that:

each State Party shall also take such measures as may be necessary to establish its jurisdiction over the above-mentioned offences when the alleged offender is present in its territory and it does not extradite him or her to another State Party on the ground that the offence has been committed by one of its nationals.

SO-CALLED AUT DEDERE AUT IUDICARE PRINCIPLE; UNODC, 2012.

This means that a state which does not want to extradite one of its citizens for an offence s/he committed abroad has to establish jurisdiction over this offence in return (UNICEF, 2009). Applying this to the above case study, 
Germany could not refuse extradition of Anna's father while he is on German territory to either the Netherlands or Canada, while at the same time not establishing jurisdiction over the offence under German law. This clause effectively limits the optional character of Art. 4(2) OPSC, as it forces Member States to apply the active personality principle if it refuses to extradite one of its nationals (UNICEF, 2009). However, this clause again aims to close any loopholes in jurisdictional matters evolving in transnational child sexual abuse cases. Lastly, Art. 4(4) OPSC states that, 'this Protocol does not exclude any criminal jurisdiction exercised in accordance with internal law'. This co-existence of jurisdiction based on international and national law reinforces the strong link between state sovereignty and jurisdiction, stressing the right of every state to regulate jurisdiction in its own way.

Even though the jurisdiction clause in the OPSC is comprehensive, it excludes cases of attempt and complicity (regulated in Art. 3(2) OPSC), by only referring to Art. 3(1) OPSC. Further, the optional character of the extraterritorial jurisdiction clause in Art. 4(2) OPSC bears the inherent risk of creating jurisdictional gaps and loopholes. Therefore, gaps and loopholes remain for matters of jurisdiction in the prosecution of offences under the OPSC.

\subsection{CRC Committee's Guidelines regarding the Implementation of the Optional Protocol to the Convention on the Rights of the Child on the Sale of Children, Child Prostitution and Child Pornography}

Given that the OPSC was adopted in 2000, it is clear that the provisions aiming to protect children from all forms of exploitation and abuse are at risk of failing to live up to the realities faced by children living in a highly digitalised and globalised world. Acknowledging the need to provide for an interpretation of the OPSC which is in line with today's realities of child sexual abuse and exploitation, the CRC Committee has recently published Guidelines regarding the implementation of the Optional Protocol to the Convention on the Rights of the Child on the sale of children, child prostitution and child pornography (hereafter: 'the Guidelines') aiming to enable a better implementation of the OPSC (CRC Committee, CRC/C/156).

With regards to jurisdiction, the CRC Committee in the Guidelines encourages State Parties to extend jurisdiction to victims with habitual residence in member states (CRC Committee, CRC/C/156). This recommendation is modelled after the jurisdiction clause in Art. 25 Lanzarote Convention, which will be discussed below. Further, State Parties are encouraged to abolish the principle of double criminality and establish universal jurisdiction over offences under the opsC (CRC Committee, CRC/C/156). 
During the drafting stage of the guidelines, the CRC Committee invited interested parties to provide written submissions on the Draft Guidelines (CRC Committee, Draft Guidelines, 2019). Austria, amongst others, criticised the recommendation to extend the range of jurisdiction clauses to cover universal jurisdiction as this might considerably violate the principle of state sovereignty (Government of Austria, 2019; Government of Japan, 2019). Even though the expansion of universal jurisdiction beyond crimes such as genocide, crimes against humanity and war crimes to "ordinary crimes" is not as uncommon as it might seem (Amnesty International, 2012), such broad jurisdiction does not solve the issue of cumbersome transnational law enforcement collaboration during the investigation stage. Therefore, Austria argued that State Parties are sufficiently equipped with the existing jurisdiction regimes (Government of Austria, 2019). In the context of the differentiation between jurisdiction to adjudicate and jurisdiction to enforce, the CRC Committee indeed seems to conflate the two terms, as the section on jurisdiction refers to 'investigate and prosecute' (CRC Committee, CRC/C/156). It has to be acknowledged that the jurisdiction to investigate exterritorialy is not governed by Art. 4 OPSC but can only be facilitated by formal and informal law enforcement collaboration mechanisms: universal jurisdiction does not mean universal investigation. Despite these concerns from Member States, the Committee in its final Guidelines maintained the section, 'encourag[ing] States parties to establish universal jurisdiction for all offences covered by the Optional Protocol' (CRC Committee, CRC/C/156).

Further, during the drafting stage, Czech Republic criticised the recommendation to abolish the double criminality standard, as this seems to be inadequate in particular in cases of the passive personality principle (i.e., jurisdiction based on the nationality of the victim), as the offender might not have been familiar with the legal framework in the country of the victim's origin. This argument has to be clearly rejected, as it gives a free pass for travelling sex offenders. Even though it is clear that the sexual offences laws vary in different countries, it seems fair to assume that people are generally aware that child sexual abuse and exploitation, in whatever form, might be considered illegal. As will be discussed below, Art. 25(4) Lanzarote Convention abolishes the double criminality requirement for offences typically committed by travelling sex offenders, as it risks considerable loopholes in the prosecution of such offences. Even though the Guidelines appreciate the necessity of such abolition in the context of travelling sex offenders, they demand the abolishment of the double criminality standard for all offences criminalised under the OPSC (CRC Committee, CRC/C/156). However, it has to be noted that the abolishment of double criminality in the Lanzarote Convention is clearly limited 
to offences typically committed by travelling sex offenders. For example, Art. 25 (4) exempts the production of 'child pornography' from the double criminality standard, but not the dissemination, possession or procuring of such material, as these are not typical offences committed by travelling sex offenders. As the double criminality standard in the context of jurisdiction aims to respect the law of the state in whose territory the crime was committed and ultimately eases the potential violation of this state's sovereignty by taking its laws into account, it might have been more balanced to adopt a limited abolition of double criminality in the Guidelines.

In summary, the Guidelines aim to interpret the opsc in light of the great technological development of the past two decades and strengthen the jurisdiction regime in transnational child sexual abuse cases. Concerns raised regarding universal jurisdiction and double criminality have not been addressed in the final version of the guidelines. Whether the Guidelines have seized the opportunity to guide Member States on child-centered jurisdiction, in particularly regarding solving jurisdictional conflicts, will be discussed below.

The 2001 Budapest Convention is the most ratified cybercrime treaty, with 65 state parties from in- and outside Europe. ${ }^{4}$ The Convention contains a comprehensive set of provisions on substantive and procedural criminal law, while additionally addressing international co-operation as a key element of the Convention. This strong commitment towards international collaboration is highlighted in the preamble, stating that 'an effective fight against cybercrime requires increased, rapid and well-functioning international co-operation in criminal matters' (Budapest Convention, Preamble). As Art. 9 Budapest Convention includes a comprehensive provision on 'child pornography', the jurisdiction clause in Art. 22 is also applicable in such cases.

Article 22 (1) a. - c. establishes jurisdiction over offences committed in the territory of a Member State, on board of a ship flying the flag of that party, or on board an aircraft registered under the laws of that party. Article 22 (1) d. extends jurisdiction to offences committed outside its territory, if the offence was committed 'by one of its nationals, and if the offence is punishable under criminal law where it was committed or if the offence is committed outside the territorial jurisdiction of any State'. In contrast to the opsC, the extraterritorial

4 See charts of signatures/ratifications/accessions here: https://www.coe.int/en/web/ conventions/full-list/-/conventions/treaty/185/signatures. Accessed 20 July 2020. 
jurisdiction clause in the Budapest Convention is fairly limited. It does not acknowledge the passive personality principle and makes the active personality principle dependent on double criminality. While the linking of extraterritorial jurisdiction with the fulfilment of the double criminality standard is common in some countries (Gilbert, 2006), it leaves a potential loophole in particular for travelling sex offenders. Given the vastly varying standards of criminalising online child sexual abuse offences (for an overview of differing legal standards, see UNODC, 2013), this extraterritorial jurisdiction clause risks that offenders go unpunished, in particular when committing an offence in a country with no or limited cyber-specific legislation. Additionally, according to Art. 22(2), state parties may reserve the right not to apply Art. 22(1) b. - d. Even though Art. 22(4) states that 'this Convention does not exclude any criminal jurisdiction exercised by a Party in accordance with its domestic law', this leaves a considerable gap for asserting extraterritorial jurisdiction for state parties.

Lastly, Art. 22 (5) addresses the issue of jurisdictional conflict. With the possibility of more than one country claiming jurisdiction over a cybercrime case, the Budapest Convention provides guidance on how to solve jurisdictional conflict. It states that:

when more than one Party claims jurisdiction over an alleged offence established in accordance with this Convention, the Parties involved shall, where appropriate, consult with a view to determining the most appropriate jurisdiction for prosecution.

The range of this provision and the solution of jurisdictional conflicts more broadly will be discussed below.

\section{Art. 25 Lanzarote Convention}

The 2007 Lanzarote Convention is the most recent international convention with a specific focus on protecting children against sexual exploitation and abuse. With a total number of 47 ratifications/accessions, ${ }^{5}$ its support from the international community lags far behind the OPSC. However, as the Lanzarote Convention was adopted in 2007, it takes more recent developments in

5 See charts of signatures/ratifications/accessions here: https://www.coe.int/en/web/ conventions/full-list/-/conventions/treaty/201/signatures?p_auth=UkZIwGUd. Accessed 20 July 2020. 
production and dissemination of child sexual abuse material into account and is hence in some regards more comprehensive than the opsc. A good example of this is the exemption of consensual sexting between minors from the scope of the 'child pornography' provision in Art. 20(3) Lanzarote Convention (for further analysis of the exemption clause, see Witting, 2019). The Lanzarote Convention takes a holistic approach by providing for a comprehensive set of preventive and responsive measures. As for the latter, the Convention addresses both substantive and procedural law, as well as international co-operation. As online child sexual abuse material is included in the substantive law chapter (Art. 20), the jurisdiction clause in Art 25. is applicable to these cases.

Article 25(1) establishes jurisdiction for offences committed on a Party's territory, on board a ship flying the flag of that Party, on board an aircraft registered under the laws of that Party, by one of its nationals or by a person who has his or her habitual residence in its territory. Regarding the last component, Art. 25(3) allows state parties to make reservations. Further, the state parties 'shall endeavour' to extend jurisdiction to offences which are committed against one of its nationals or a person who has his or her habitual residence in its territory. This is in line with the proposal of the CRC Committee in the Guidelines discussed above. However, it has to be noted that this extension to passive personality principle and residents of a party's territory is a recommendation, rather than a mandatory standard such as Art. 25(2) ('shall endeavour') (Council of Europe, 2007). In order to combat offences typically committed in the context of sex tourism, Art. 25(4) states that for cases of production of 'child pornography', amongst others, parties shall ensure that the double criminality standard is not applicable. As discussed above, this is in line with the recommendation made by the CRC Committee in its Guidelines. Complementing the abolition of double criminality in offences typically committed in the context of sex tourism, Art. 25(6) makes it obligatory for parties to ensure that its jurisdiction is not dependent on a report from the victim or a denunciation from the state in which the offence was committed. This should ensure that in a situation whereby the state in which the offence was committed is not willing or capable of investigating the matter, the state whose national committed the offence can still claim jurisdiction. Apart from the aut dedere aut iudicare clause in Art. 25(7), the Convention in its Art. 25(8) states that in case of more than one state claiming jurisdiction over a case, the states shall, where appropriate, consult to determine the most appropriate location of jurisdiction. This will be discussed in more detail below.

In conclusion, Art. 25 provides for a comprehensive set of provisions to expand extraterritorial jurisdiction to both active and passive personality principle, including offenders and victims who merely are habitual residents. 
The additional provisions applicable to offences typically committed in cases of travelling sex offenders show that the Lanzarote Convention adequately responds to the transnational nature of child sexual abuse and exploitation with regards to jurisdiction.

\subsection{Determining (Extra)Territoriality in Cyberspace}

While the above sections describe the various jurisdiction regimes in the OPSC, Budapest and Lanzarote Convention, it is important to note that the application of these principles in actual cases is not as easy as it might seem. As discussed above, jurisdiction was traditionally based on the notion of territorial sovereignty. If an offence took place within a country's borders, territorial jurisdiction was established. While it is relatively easy to determine whether cattle had been stolen on the one or the other side of the border, the nature of cyberspace considerably complicates the determination of intra- and extraterritoriality. As will be shown, the sui generis character of cyberspace leads to the effect that many can claim jurisdiction over a cybercrime offence, even though the link might seem fairly remote.

One aspect used by many countries to establish a link between the offence and its territory is to determine the location of the act(s) (Brenner/Koops, 2004; UNODC, 2013). Attempting to locate where the act of disseminating child sexual abuse material took place in the above case study, ${ }^{6}$ one could argue that the material was uploaded in Canada, and that therefore the act took place on Canadian territory. On the other hand, the act was initiated in Canada, but only completed once the material actually reached the end user. In our case, this would enable South African authorities, amongst all other countries in which the material was accessed, to claim jurisdiction. Further, as the content was uploaded to an American server, and the processing of the data is key to both initiate and complete the dissemination of the material, it could be argued that the substantial part of the act took place in the US. Given that the location of the act is ultimately determined by national courts when interpreting the jurisdiction clause in national legislation, it is fair to say that Canada, America and South Africa could all claim territorial jurisdiction over Anna's case. This shows that a single location is not, in most cases, determinable.

Apart from using the location of the act to determine territorial jurisdiction, countries in their national legislation use location of the computer, location of persons involved, or simply a harmful effect on its territory to determine

6 The contact offence and the production of child sexual abuse material clearly took place on Canadian territory. These offences need to be separated from the dissemination of child sexual abuse material online through uploading. 
territorial jurisdiction (Brenner/Koops, 2004; UNODC, 2013). Adding extraterritorial jurisdiction claims based on active and passive personality principle to the above territorial jurisdiction claims, Canada, America, South Africa, Germany, the Netherlands and all other countries in which the material depicting Anna's sexual abuse was accessed or downloaded could claim jurisdiction over the case. This sheer magnitude of (legitimate) adjudicatory jurisdiction claims is rooted in the fact that ultimately, states can regulate jurisdiction as extensively as they wish. The notion of respect for other countries' sovereignty is not a limiting factor on a national level, hence national legislation cannot be measured against any conflicting superior law. Even international law such as the opsc, Budapest Convention and Lanzarote Convention acknowledge that their proposed jurisdiction clauses do not undermine existing clauses in national legislation. This strong protection of jurisdictional discretion should, on the one hand, be welcomed, as a jurisdictional gap seems unlikely, but might also cause jurisdictional conflicts. These will be discussed in the next section.

\subsection{Jurisdictional Conflicts}

Given the various sources of jurisdictional claims in the area of online child sexual abuse offences, jurisdictional conflicts seem inevitable.

As mentioned above, both the Budapest and the Lanzarote Convention contain clauses on jurisdictional conflict. According to Art. 22(5), parties shall where appropriate - consult with a view to determine the most appropriate jurisdiction. As the wording indicates, this obligation is not absolute, but will depend on the specific case (Council of Europe, 2001). The jurisdictional conflict clause in the Lanzarote Convention is worded and interpreted similarly (Council of Europe, 2007). This generic clause does not, unfortunately, provide sufficient guidance on how to concretely resolve jurisdictional conflicts, as guiding factors are missing.

Therefore, the "rule of reason" has been introduced to solve jurisdictional conflicts in cybercrime cases (Ryngaert, 2015). The "rule of reason" implies that the valid assertion of jurisdiction will only be lawful if exercised reasonably, i.e., after State courts and regulators have balanced the different interests involved in a transnational situation before establishing their jurisdiction and - quite probably - applying their own law. Ultimately, the "rule of reason" aims at 'identifying the State with the strongest connection, in terms of contacts or interests, with the situation' (Ryngaert, 2015). The obvious flaw of this "rule of reason" is its subjectivity. What is considered the strongest connection in a specific case, can and will be interpreted differently by various states (Ryngaert, 2015). Further, given that the rule 
will be interpreted by the judiciary and the subject matter touches upon political questions around foreign relations and hence on the core business of the executive, it might cause potential unease within the different branches of government against the background of separation of power (Ryngaert, 2015).

This shows that there is a clear need for internationally agreed factors which guide the negotiations between states in determining the closest link to the case (Brenner/Koops, 2004). Given that cases dealing with online child sexual abuse material produce highly traumatised (child) victims, it is submitted that the "rule of reason" in such cases should not necessarily aim to establish which state has the closest link to the offence, but rather which state can best serve the interests of the child victim. Child-centered factors aiming at putting the best interests of the child victim at the centre of the negotiations will therefore be discussed below.

\section{Mutual Legal Assistance and Extradition}

Once a state has established its jurisdiction to adjudicate, it starts the investigation of the online child sexual abuse case at hand. Due to the transnational nature of such offences, the state might be dependent on gathering evidence which is located outside its territory. As discussed previously, the jurisdiction to investigate is rooted in the principle of sovereignty of states (Brenner/ Koops, 2004; Brenner, 2012). Therefore, if State A intends to investigate a crime on the territory of State B, State B needs to generally give consent to such an investigation (Oerlemans, 2017; Osula (b), 2015).

The volatile nature specifically of digital evidence requires a prompt and efficient transnational law enforcement mechanism to obtain such consent (Osula (a), 2015). Such mechanism is key to ensure that online child sexual abuse offences are investigated beyond and despite country borders. Traditionally, such transnational collaboration is facilitated by mutual legal assistance (hereafter: MLA) and extradition requests. Mutual legal assistance in criminal matters is hereby defined as 'a process by which States seek and provide assistance in gathering evidence for use in criminal cases' (UNODC, 2012). Extradition is considered:

the formal process by which one jurisdiction asks another for the enforced return of a person who is in the requested jurisdiction and who is accused or convicted of one or more criminal offences against the law of the requesting jurisdiction.

UNODC, 2012 
Acknowledging the volatile nature of such evidence on the one hand, and the delay in obtaining such evidence caused by formal requests on the other hand, the state's interest to protect its sovereignty often times clashes with the need for speedy and efficient transnational procedures. Therefore, law enforcement does not only rely on traditional mutual legal assistance and extradition requests, but a variety of informal or accelerated means to obtain extraterritorial evidence. Given the sui generis character of cyberspace, and with it the conflation of intra- and extraterritoriality, this article will explore how formal and informal collaboration mechanisms are regulated in the opsc, Budapest and Lanzarote Convention.

\subsection{Introduction to Mutual Legal Assistance and Extradition Mechanisms}

MLA and extradition regimes are in most countries governed by a two-pronged system, national legislation and bi- or multi-lateral treaties. While the national legislation sets out the domestic procedure for facilitating the requests, many countries require a bi- or multi-lateral treaty regulating and legitimising such requests on a transnational level with the requesting or receiving state (UNODC, 2012; Oerlemans, 2017). This dual legal regime of MLA and extradition poses significant challenges to state collaboration, as it puts the threshold for satisfying the legal requirements of both states fairly high. Acknowledging that it is very cumbersome for a state to enter into bi-lateral agreements with potentially any other state in the world (UNODC, 2012), the role of MLA and extradition clauses in multi-lateral treaties such as opsc, Budapest and Lanzarote Convention cannot be overestimated.

Further, the traditional MLA and extradition processes were developed in the 1970s, hence before the era of cybercrime (Osula (a), 2015). Therefore, they might not be tailored towards such a constantly developing and emerging field, as they do not take the volatile nature of digital crime scenes into account. Formal processes in particular in the area of MLA take long and are cumbersome. It can take months and years to finally obtain crucial evidence needed for an ongoing investigation (Maillart, 2019; Osula (a), 2015; Pullen, 2018). Given that in online child sexual abuse cases the depicted child might be under continuous threat of further abuse and exploitation, this situation puts immense pressure on law enforcement.

As mentioned above, further bottlenecks are the varying legal standards on national level regarding the requirements and processes of MLA and extradition requests. Even though an analysis of national level legislation exceeds the scope of this publication, it is important to note that national legislation applicable to MLA and extradition in cybercrime cases exists in two thirds of countries in Africa, Asia and Oceanica, and in almost all countries in Europe 
(UNODC, 2013). However, most legislation is not cyber-specific (UNODC, 2013). Keeping in mind that the majority of countries are not part of cyber-specific multi-lateral treaties, the execution of specialised cybercrime investigation is considerably hampered (UNODC, 2013). Additionally, the capacity on national level to execute such requests, in particular with regards to conducting cyber-specific investigation and evidence collection, varies greatly between countries and adds an additional barrier in the executing stage (UNODC, 2013).

Even though this introduction might paint a grim picture of the status of MLA and extradition regimes in the area of cybercrime in general and online child sexual abuse in particular, there is an urgent need to conceptualise existing regimes and re-think traditional concepts in order to make them suitable for investigating online child sexual abuse cases. Against this background, the next section will analyse the range and challenges of MLA and extradition clauses in the OPSC, Budapest and Lanzarote Convention. Further, we will explore child-centered standards in the execution of such requests which ensure a child-friendly and victim-oriented criminal justice procedure.

\subsection{Mutual Legal Assistance (MLA) and Extradition in Relevant International Conventions}

This section will analyse the MLA and extradition regulations in the OPSC, Budapest Convention and Lanzarote Convention. While the OPSC and Lanzarote Convention provide only for a skeleton of extradition and MLA clauses, the Budapest Convention provides for a comprehensive and cyberspecific set of collaboration regimes.

MLA and extradition are regulated in Arts. 5-7 and Art. 10 OPSC. This section will analyse the wording and interpretation of the relevant MLA and extradition provisions and discuss the expansion of these provisions to cases of mere possession and accessing of online child sexual abuse material.

\subsection{Wording and Interpretation}

Article 5(1) OPSC states that offences referred to in Art. 3(1) OpSC shall be considered extraditable offences in existing extradition treaties and shall be included as extraditable offences in future extradition treaties. The reference 
to Art. 3(1) OPSC shows that this should not apply to attempt of and complicity to commit child prostitution, sale of children and child pornography offences, as these are regulated in Art. 3(2) OPSC (UNICEF, 2009). However, the CRC Committee encourages state parties to extend the application of extradition provisions to Art. 3(2) OPSC offences (CRC Committee, CRC/C/156). Article $5(2)$ OPSC states that in case a state party makes extradition dependent on the existence of an international treaty, the OPSC shall serve as legal basis for such an extradition request. Given that 176 states have ratified the opsc, ${ }^{7}$ this provision can facilitate extradition between these states, subject to their respective domestic legislation. Additionally, in case a state does not make extradition dependent on the existence of a treaty, the state party should recognise Art. 3(1) OPSC offences as extraditable offences according to Art. 5(3) opSC. Article 5(5) OPSC concludes with the aut dedere aut iudicare principle (CRC Committee, CRC/C/156).

When it comes to MLA requests, the provisions in the OPSC are rather generic. Article 6(1) OPSC states that state parties shall, 'afford one another the greatest measure of assistance in connection with investigations or criminal or extradition proceedings, ... including assistance in obtaining evidence'. Finally, Art. 1O(1) OPSC requests states to 'take all necessary steps to strengthen international cooperation by multilateral, regional and bilateral arrangements for the ... investigation, prosecution and punishment' of Art. 3(1) OPSC offenders. This should extend to law enforcement and the judiciary, but also to partnerships with private sector and csos to develop technical solutions to improve investigation and prosecution (CRC Committee, CRC/C/156). The OPSC provides for a strong extradition, but a very generic MLA regime. The shortages in the MLA provisions can be interpreted as an indication that the phenomenon of online child sexual abuse offences during the time of the drafting of the protocol in the 199os was only recently discovered (UNICEF, 2009).

\subsection{Expansion to Mere Possession and Accessing?}

Given the importance of these regimes in terms of online child sexual abuse cases, the CRC Committee in its Guidelines envisioned strengthening some of the generic provisions (see, for example, concrete proposals for international cooperation in CRC Committee, CRC/C/156). However, one major gap in the Guidelines is the non-extension of the OPSC extradition and MLA provisions to cases of mere possession and accessing of child sexual abuse material. The mere possession and accessing of child sexual abuse material

7 See full list of ratifications/accessions here: http://indicators.ohchr.org. Accessed 19 August 2019 . 
is not criminalised by Art. 3(1) c) OPSC ('producing, distributing, disseminating, importing, exporting, offering, selling or possessing [child pornography] for the above purposes') (Witting, 2020). In our case study, the South African client who downloaded Anna's material only possessed it for his private use, hence not 'for the above purposes' such as distributing, disseminating, importing, exporting, offering or selling. Following the wording of the extradition and MLA clauses in Art. 5(1) and Art. 6(1) OPSC, any extradition or MLA request extended to South African authorities could not be based on the opsc. The same applies to the live-streaming of child sexual abuse material, as the accessing of material without possession for further purposes is also not covered by Art. 3(1) OPSC. Given that, in particular, live-streaming of child sexual abuse is an emerging trend (ECPAT, 2018), the OPSC leaves a considerable gap for extradition and MLA requests in such cases.

Therefore, in order to prioritise the best interests of the child principle set out in Art. 3 (1) of the Convention on the Rights of the Child, it is recommended that the MLA and extradition provisions in Arts. 5-7 and Art. 10 OPSC should be interpreted to cover not only Art. 3(1) OPSC offences, but also attempt and complicity to commit such offences as set out in Art. 3(2) OPSC as well as the mere possessing and accessing of child sexual abuse material.

Article 23-Article 35 BC

The Budapest Convention is the only international treaty which provides for cyber-specific MLA and extradition provisions (Osula (a), 2015). Chapter III (International co-operation) contains extradition and a wide range of MLA provisions, even for the situation in which no MLA treaty exists between the parties. Specific provisional MLA regulations are complemented by a $24 / 7$ network for speedy assistance amongst parties. As the in-depth discussion in particular of the MLA provisions exceeds the scope of this publication, this section will mainly focus on Arts. 23-25 Budapest Convention, and provide for a brief overview of the additional MLA provisions in Arts. 26-35 Budapest Convention.

Art. 23 provides for three general principles with regards to international co-operation. First, international collaboration should be provided 'to the widest extent possible'. Secondly, the scope of the provisions in Chapter III are not limited to the offences set out in the substantive criminal law provisions (Arts. 2-12) but apply to 'criminal offences related to computer systems and data, or for the collection of evidence in electronic form of a criminal offence' (with the exception of Art. 24, Art. 33 and Art. 34). This wording excessively extends 
the applicability of Chapter III, as it applies to any offence involving a computer system or data, or any form of electronic evidence (Council of Europe, 2001). ${ }^{8}$ This broad range of application, and therewith flexibility of interpretation, allows for an evolving applicability of the provisions, dynamically following the latest developments in the area of cybercrime. Lastly, the parties shall co-operate:

in accordance with the provisions of this chapter and through the application of relevant international instruments on international co-operation in criminal matters, arrangements agreed on the basis of uniform or reciprocal legislation, and domestic laws.

This confirms the principle that any existing international or national cooperation mechanism shall not be superseded by the Budapest Convention (Council of Europe, 2001).

The extradition clause in Art. 24 is, according to paragraph 1 , only applicable with regards to offences established in Arts. 2-11 Budapest Convention, and only if they are punishable with a minimum sentence of one year according to the law of both parties concerned. Art. 24(2) requires state parties to include these offences as extraditable offences in any existing and future extradition treaty. According to Art. 24(3), parties can use the Budapest Convention as a legal basis for extradition, if a party makes extradition conditional upon the existence of an international treaty. Further, extradition shall be subject to the conditions provided for by the law of the requested party or by applicable extradition treaties (Art. 24(5)), and the aut dedere aut iudicare principle is embedded in Art. 24(6) (Council of Europe, 2001). Lastly, Art. 24(7) requires all state parties to communicate the name and address of the authority in charge of making and receiving extradition requests. This aims to ensure the smooth and timely processing of extradition requests, in particular in situations where there is no extradition treaty between the involved parties (Council of Europe, 2001).

8 Criticising this broad range as the Budapest Convention does not provide for safeguards regarding the proportionality of the intervention, Hosuk Lee-Makiyama, A Multilateral Legal Assistance Protocol: Preventing Fragmentation and Re-territorialisation of the Internet, ECIPE Policy Briefs No. 9/2013:. 6; criticising the outsourcing of general proportionality standard to domestic law, while providing for intrusive procedural measures on international level, Miriam F. Miquelon-Weismann, "The Convention on Cybercrime: A Harmonized Implementation of International Penal Law: What Prospects for Procedural Due Process?", Marshall Journal of Computer and Information Law 2005 (23), 355 et seq. 
On top of these generic extradition and MLA clauses, the Budapest Convention provides for a set of additional MLA clauses, focusing on MLA in absence of a MLA treaty (Arts. 27-28), MLA regarding provisional measures (Arts. 29-30) and MLA regarding investigative powers (Arts. 31-34). Arts. 27 and 28 only apply if there is no other existing MLA regime between the parties which could be leveraged for the request. The drafters of the Budapest Convention decided against the establishment of a general MLA regime, which could be applied in the absence of an existing treaty, arguing that this could lead to confusion amongst parties about competing MLA regimes (Council of Europe, 2001). However, in order to provide state parties with an instrument for rapid response in "emergency" situations, Arts. 27 and 28 provide for rules and procedures regarding the request and execution of MLA requests outside of an existing MLA regime, including imposing of conditions, grounds of refusals, confidentiality of requests, limitation of use and direct communication (Council of Europe, 2001).

Further, the Budapest Convention provides provisional measures for the preservation of data in Arts. 29 and 30 , which take the volatile nature of digital evidence into account (Osula (a), 2015). Notably, a requested party can expedite the preservation of computer data stored in its territory, while the requesting party is preparing the official MLA request, to ensure the data is not altered, removed or deleted (Council of Europe, 2001; according to Weber, 2003, procedural errors in the preservation of the data can still be cured before the data is officially handed over). Lastly, Arts. 31-34 Budapest Convention provide for a comprehensive set of MLA provisions regarding investigative powers, including the accessing of stored computer data on another party's' territory (Art. 31), transborder access to stored computer data without consent or where publicly available (Art. 32), real time collection of traffic data (Art. 33) and interception of content data (Art. 34). The provisions aim to strike a balance between the protection of state sovereignty and the need for prompt and efficient transborder investigation of cybercrime.

In view of its broad set of extradition and MLA provisions, the Budapest Convention is clearly tailored to the specific needs of addressing cybercrime. In order to strengthening further the MLA regime in the Budapest Convention, the Council of Europe in 2017 started the process of drafting a second additional protocol to the Convention, which focuses - inter alia - on developing simplified MLA procedures, facilitates direct cooperation between judicial authorities in MLA requests and establishes joint investigations and investigation teams (Council of Europe, 2017). In conclusion, the Budapest Convention remains the only international cybercrime treaty with cyber-specific MLA and extradition provisions, even though some of its provisions might be outdated by now. 
The international cooperation chapter in the Lanzarote Convention is fairly short and only consists of general principles and measures for international cooperation. Given that the Council of Europe has put a comprehensive set of MLA and extradition treaties in place, ${ }^{9}$ the drafters felt that there was no need to duplicate this comprehensive set of regulations (Council of Europe, 2007). This reasoning is obviously based on the belief that most parties who are party to the Lanzarote Convention are also party to these EU specific MLA and extradition treaties, which creates a potential gap for state parties who only ratify the Lanzarote Convention.

Article 38(1) requests state parties to collaborate with each other to the 'widest extent possible' in the areas of prevention, protection and investigations concerning the offences established in this Convention. Article 38 (2) establishes a mechanism whereby victims can file a complaint before the competent authorities in their state of residence, even if the offence was committed outside the territory of the state of residence. The state of residence can then decide whether it intends to take the case forward or refer the case to the authorities in the country where the offence took place. This victim-friendly procedure aims to make it easier for victims to report offences under the Lanzarote Convention (Council of Europe, 2007). Further, Art. 38(3) states that in case state parties require a bilateral treaty to facilitate MLA or extradition requests, they 'may consider this Convention the legal basis for mutual legal assistance in criminal matters or extradition in respect of the offences established in accordance with this Convention'. This provision bridges the gap between state parties in- and outside of the EU, which are not connected through any of the above-mentioned EU MLA and extradition treaties.

\section{$9 \quad$ Child Specific Considerations in Transnational law Enforcement}

Acknowledging the specific vulnerabilities and needs of child sexual abuse victims, both the determination of the appropriate jurisdiction and the procedure of MLA and extradition in online child sexual abuse cases should require involved states to apply a child-centered lens to all their proceedings. As has

9 For example, the European Convention on Extradition (ETS 24), the European Convention on Mutual Assistance in Criminal Matters (ETS 30), their Additional Protocols (ETs 86, 98, 99 and 182), and the Convention on Laundering, Search, Seizure and Confiscation of the Proceeds from Crime (ETS 141). 
been shown above, there is a strong need for the provision of factors to solve a situation of conflict of jurisdictions, following the best interests of the child principle. Simultaneously, MLA and extraditions need to be carried out in a child-friendly and victim-centered manner. Therefore, this section attempts to provide for recommendations and benchmarks as to how transnational law enforcement collaboration in the area of jurisdiction, MLA and extradition should be facilitated in order to uphold the best interests of the child as paramount consideration. First, this section will discuss the best interests of the child in the criminal justice process more generally, before elaborating on its application in the specialised areas of jurisdictional conflicts, extradition and mutual legal assistance.

\subsection{Best Interests of the Child in the Criminal Justice Process}

The best interests of the child is a principle, a substantive right and a rule of procedure (CRC Committee, $\mathrm{CRC} / \mathrm{C} / \mathrm{GC} / 14$ ). In terms of the latter, this means that in any decision-making process, the impact of the decision on the child must be evaluated. Generally speaking, the best interests of the child principle in the context of the criminal justice system means protection from (future) abuse and exploitation, prioritising the harmonious development of the traumatised child victim as well as ensuring that the child's views, opinions and concerns affecting his or her life are heard (UN Economic and Social Council, E/CN.15/2005/L.2/Rev.1; UN General Assembly, Declaration of Basic Principles of Justice for Victims of Crime and Abuse of Power, E/AC.57/1990/3). It is important to note that the best interests of the child principle concerns both the interests of the individual child victim as well as the interests of children as a group. In the context of protection from (further) abuse and exploitation, this means for the individual child that all measures have to be taken so that the child is not further violated, either by the same or by any other perpetrator. For children as a group, it is important that persons who previously abused children are prevented from future offences, and that the criminal justice system sends a signal to society that child sexual abuse and exploitation do not go unpunished. With regards to prioritising the harmonious development of the traumatised child, it means that procedures need to be put in place which ensure a child-sensitive criminal justice procedure that avoids the creation of any secondary trauma. Such a child-centered procedure allows authorities on an individual level to make the vulnerabilities of the individual child in each case the primary consideration when deciding on which procedure to follow. Lastly, regardless of the age, the developmental level or any particular vulnerability of the child victim, the child's views need to be taken into consideration (CRC Committee, CRC/C/GC/14; UNODC, 2005). A child's right to 
participation as guaranteed in Art. 12 CRC in the context of the criminal justice system includes the opportunity to express:

their views and concerns regarding their involvement in the justice process, their concerns regarding safety in relation to the accused, the manner in which they prefer to provide testimony and their feelings about the conclusions of the process.

UN ECONOMIC AND SOCIAL COUNCIL, E/CN.15/2005/L.2/REV.1

This means that children as a group need to have the right to voice their views and opinions concerning the criminal justice process, as set out in the relevant, child-friendly criminal procedure. For the individual child, support systems need to be in place which actually enable the individual child meaningfully to participate in the criminal justice system without experiencing additional hardship.

As transnational law enforcement collaboration, including jurisdiction, extradition and mutual legal assistance, form part of the criminal justice process, the principles set out above equally apply in this context. However, there is need to take the specific objectives and challenges of transnational law enforcement collaboration in the context of online child sexual abuse into account. The following sections are a first attempt for putting the best interests of the child principle at the center of transnational law enforcement collaboration in the context of online child sexual abuse offences, focusing on solving jurisdictional conflicts, mutual legal assistance and extradition. Developing these general principles further will make them relevant and useful for this specific area of the criminal justice process.

\subsection{Solving Jurisdictional Conflicts in a Child-centered Way}

As discussed above, jurisdictional conflicts might regularly occur in the context of online child sexual abuse, as states might be claiming territorial or extraterritorial jurisdiction over the case. The "rule of reason" is currently applied to resolve jurisdictional conflicts between states in cybercrime cases, aiming to establish which state can reasonably show the closest connection to an offence by applying territoriality as decisive factor. Keeping in mind the difficulties in determining where the offence was committed in the first place, and given that online child sexual abuse has a tremendous impact on the physical and mental well-being of the child victim (Gewirtz-Meydana/Walsha/Wolanka/ Finkelhora, 2018), focusing merely on where the offence took place does not seem appropriate given the various needs of the child victim in the criminal justice process as laid out above. 
Therefore, it is submitted that the "rule of reason" approach in such cases should not only focus on the closest connection to a state's territory but needs to establish which state can best serve the interests of the child victim. This section aims to provide factors which can guide states in determining which jurisdiction is most suitable to serve the best interests of the offended child. Hereby, an ecological approach is suggested, which holistically assesses the child's situation on an individual, family, community and societal level (UNICEF, 2019). As indicated earlier, the best interests of the child have to be determined on a case-by-case basis, depending on the individual experiences of the concerned child, the situational circumstances as well as the weight of each factor in the specific case. It therefore takes the child's identity and child's needs as the starting point, while also considering the situation of the child's family and community as well as the child-friendliness of the criminal justice system (UNICEF, 2019). This approach will also draw on the factors established by the CRC Committee aiming to assist in determining the best interests of the child (CRC Committee, CRC/C/GC/14).

The list of factors below is not exhaustive and not all factors need to be considered in each and every case. It is, rather, conceptualised as an aid in determining which factors are relevant in order to ensure that the jurisdictional conflict is solved in the best interests of the offended child. It also does not mean to propose that cases should never be prosecuted in the territory where the offence took place. Given that most evidence might be found where the offence was committed, there are many advantages in prosecuting the offence on that state's territory. However, in order to serve the best interests of the individual child, each and every case needs to be considered holistically and, given the vulnerability of child victims, the determination of the jurisdiction most suitable to serve the interests of the child needs to go beyond solely focusing on territory. Therefore, the factors below aim to effect a mind-shift away from a purely territory-focused to a child-focused "rule of reason" test in solving jurisdictional conflicts. In order to make this approach more concrete, Anna's case is used as an example to showcase how these factors can be applied in order to solve a jurisdictional conflict in a child-centred manner.

\section{Child's Identity and Needs}

The child's identity should be at the core of assessing the best interests of the child in terms of determining the most reasonable place of jurisdiction. This includes - inter alia - their situation of vulnerability and need for safety and protection (CRC Committee, CRC/C/GC/14). Children who have experienced 
online sexual abuse might face considerable mental and physical consequences (Gewirtz-Meydana/Walsha/Wolanka/Finkelhora, 2018; Ghimire/ Follette, 2012; UNODC, 2015). In order to stabilise children and assist them to recover from the abuse, a consistent and supportive environment is key. This is further exacerbated by the developmental stage of the child, as the stability and consistency in the immediate environment is even more important for younger children. Further, a child's general vulnerability will play a key role, e.g. whether the child is living with a disability, needs access to special medicines or medical services etc. (CRC Committee, $\mathrm{CRC} / \mathrm{C} / \mathrm{GC} / 14$ ).

These factors come into play when determining the most suitable place of a jurisdiction, as the assertion of jurisdiction outside of the child's country of residency might mean that the child is removed from its usual environment in order to participate in the criminal justice process. This could have a negative impact on the child's overall wellbeing, as removing the child from its usual environment might be interpreted by the child as punishment. Consequently, the child's confidence might be hampered and the quality of its statement might be impacted. Such "removal" in its most extreme case could mean that the child is participating in the criminal justice process in another country in persona. As another example, countries use video links for foreign victims to participate in the country's criminal justice process. This might require the child victim to travel from the rural areas to the capital, in order to give evidence via video link at the state's embassy. Even such seemingly small movements might be stressful and disruptive for the child's recovery, and should hence carefully be considered.

Relating these factors to the above case study, Anna's developmental stage and her strong need for consistency as a seven-year old child needs to be taken into account. Further, given that the contact offence (i.e. sexual abuse) as well as the production and (at least partly) the dissemination of the child sexual abuse material took place on Canadian territory, and assuming that Canada would assert jurisdiction, Anna might feel like she is being punished by being forced to return to (or at least collaborate with) the country where the abuse took place. This might have an overall negative impact on her willingness to participate in the criminal justice process and/or the quality of her testimony.

\section{Role of Family and Community}

Further, the child's relationship to its family and community are crucial to assess which location of jurisdiction serves their best interests. A child's family and community are the environment in which the child understands, relates 
and associates. As the overall stability of this context influences the resilience of the child and the chances for recovering from the abuse, the consistency of the child's position in the family and the community needs to be considered. Many survivors of child sexual abuse wish to return to a sense of "normality": they want to live a life like other children who have not been sexually abused (ECPAT, 2017). Access to health services, including psychological or therapeutic support, and access to the education system, are considered part of the community environment and hence the structure of a child's daily life (ECPAT, 2017). In particular in a context whereby the sexual abuse was committed by a family or community member and the child's relationship to these systems is therefore jeopardised, the reintegration and re-establishment of the child's relationship and trust to family and community is key. ${ }^{10}$ Healing the "relational injury" is a precondition to re-establishing the child's ability to bond with others (Hunter, 2010). This process should not be constrained by removing the child from this context, even if it is only for a short period of time. In this context, the impact of interrupting the child's therapy or schooling needs to be considered as well.

In Anna's case, the fact that her father was involved in the abuse will considerably impact the family situation. These negative effects on the stability and healthiness of the family life require a considerable amount of reintegration and redefinition efforts by Anna and her family. This might also extend to the community in a broader sense. This means that removing Anna from this familiar context is even more difficult as the trust she had in her support structure might be considerably hampered through the intrafamily abuse.

Zooming out from the child's identity and the family and community environment, another factor to take into consideration when determining the most appropriate location of jurisdiction in online child sexual abuse cases is the child-friendliness of the criminal justice system at hand. The ultimate aim of establishing a criminal justice system which is tailored towards the needs of children in general is to ensure accountability of offenders, prevent further abuse and exploitation and, lastly, ensure that the child's voice is heard. The

10 In the general context of stability and child development stating that 'the higher the levels of instability are within a family, the higher the levels of maladjustment that can be expected, Stephen Baldridge, Family Stability and Childhood Behavioral Outcomes: A Critical Review of the Literature, Journal of Family Strengths, Vol. 11 (2011), p. 9. 
latter is particularly important in child sexual abuse cases, as having their voices heard assists children in gaining control back, which they were deprived of during the period of the sexual abuse (ECPAT, 2017). As mentioned above, safeguarding the child's best interest in the criminal justice process means, inter alia, that the harmonious development of the traumatised child is prioritised, and secondary trauma is avoided by all means. Translating this into concrete measures, the child's experience in the criminal justice system can be significantly improved through interventions such as meaningful and childfriendly court preparation, testifying via CCTV camera systems, presence of an intermediary or support person, access to and quality of social welfare support structure more broadly, avoidance of direct confrontation with the alleged perpetrator, and the replacement of testimony by video or audio tape, inter alia (UN Economic and Social Council, E/CN.15/2005/L.2/Rev.1; UNODC/UNICEF, 2005). Another crucial factor is the speediness of the justice system, and the pre- and post-trial care (UNODC/UNICEF, 2015).

As these factors are based on national legislation, an in-depth analysis of the child-friendliness of the criminal justice system in Canada and other countries involved in Anna's case exceeds the scope of this publication. Some relevant factors which needed to be determined would be whether Anna would have to appear in the Canadian court in persona, or if she could give testimony via video link (for example, from a Canadian embassy). If the latter is possible, the next question is whether she would be directly connected to the court room (and hence possibly face the alleged perpetrator, even though only through video link), or whether she would be shielded from direct contact and exposure to the alleged perpetrator. In addition, it would have to be determined which pre- and post-trial care could be offered to Anna. This form of critical analysis should be applied for all countries claiming jurisdiction.

\section{Towards a Holistic Child-centered Solution for Jurisdictional Conflicts}

Once the specific vulnerabilities of the child victim, as well as the child-friendliness of the criminal justice systems at hand, have been identified and analysed, the factors need to be brought together to form a holistic assessment as to which country can best serve the interests of the child victim, and should hence claim jurisdiction in accordance with the proposed child-centered "rule of reason" approach. As described by the CRC Committee in the context of balancing the elements in the best-interests assessment generally, 
the content of each element will necessarily vary from child to child and from case to case, depending on the type of decision and the concrete circumstances, as will the importance of each element in the overall assessment.

CRC COMMITTEE, CRC/C/GC/14

A thorough analysis of each case following the above elements is therefore key to develop a balanced, child-centered "rule of reason" decision.

It is acknowledged that this proposed child-centered "rule of reason" approach is much more complex than simply determining which country is most closely linked to the case based on territorial considerations. However, it is submitted that such a holistic assessment is the only way to uphold the best interests of the child principle in the context of jurisdictional conflicts. Given that little has been written about the best interests of the child principle in the context of transnational law enforcement collaboration, and jurisdictional conflicts in particular, international guidance on such a child-centered "rule of reason" approach is crucial to ensure consistent application of such an approach across countries.

Unfortunately, the CRC Committee seems to endorse the solely territorybased "rule of reason" approach, by stating that, 'the State in which the offence was committed is primarily responsible for the investigation and prosecution of the offender' (CRC Committee, CRC/C/156). An important opportunity for introducing an international child-centered "rule of reason" approach to jurisdictional conflicts has hence been missed. Given the need to update the CRC Committee Guidelines on a regular basis to ensure they speak to the reality on the ground (Skelton and Mezmur 2019), it is submitted that this child-centered "rule of reason" approach should be considered in the next version of the Guidelines.

\subsection{Child-Friendly Procedures in MLA and Extradition Procedures}

Referring back to the above case study, and assuming that Canada would assert jurisdiction over Anna's case, the Canadian police would have to collaborate with the Dutch police on obtaining Anna's statement and facilitate Anna's testimony during trial stage. If Canadian authorities leverage international collaboration clauses in the OPSC, Budapest or Lanzarote Convention for this, the question arises whether the international conventions lay down any minimum standards on how Anna's rights and interests as a child victim should be protected during the execution of the international collaboration request.

As for the OPSC, Art. 8 provides for a detailed catalogue of measures state parties shall adopt to protect the rights and interests of children during the criminal justice process, including adopting of procedures which recognise the specific 
needs of child victims and witnesses, providing appropriate support services during the criminal justice process, and allowing the views, concerns and needs of the child to be presented throughout the process. Based on Art. 8 opsc, the United Nations Economic and Social Council Guidelines on Justice in Matters involving Child Victims and Witnesses of Crimes (UN Economic and Social Council, E/CN.15/2005/L.2/Rev.1) detail child-friendly criminal procedures, e.g. the use of ССтv in court rooms or video and audio recordings of their statement. Similarly, Art. 31, Lanzarote Convention sets out general measures of protection in criminal justice proceedings, with Arts. 35 and 36 Lanzarote Convention even providing detailed minimum standards on interviewing child witnesses and appropriate criminal procedures for child sexual abuse and exploitation cases. On the other hand, the Budapest Convention does not provide for any provision on safeguarding vulnerable victims throughout the criminal justice process. Given that the vast majority of Articles in the Budapest Convention deal with procedural matters, this is somewhat surprising.

However, taking the above analysis of the range of extradition and MLA provisions on the one hand, and the child safeguarding provisions on the other, into account, it is clear that both OPSC and Lanzarote Convention considerably lack cyber-specific or cyber-appropriate international collaboration mechanisms, while providing for sufficient child safeguarding mechanisms during the criminal justice procedure. In contrast, the Budapest Convention provides for a comprehensive set of cyber-specific M LA and extradition provisions, while not even mentioning the specific needs and concerns of vulnerable witnesses.

\section{Conclusion}

Anna's case - similar to many other cases of online child sexual abuse and exploitation - shows the complexity of (extra)territorial jurisdiction and law enforcement collaboration across country borders. Even though territorial and extraterritorial jurisdiction clauses are included in the opsc, Lanzarote Convention and Budapest Convention, it is clear that the devil lies in the detail. And unfortunately, the complex details of determining jurisdiction and the solving of jurisdictional conflicts is mainly discussed in the broader context of cybercrime offences, without taking the specific vulnerability of child sexual abuse victims into account.

Similarly, MLA and extradition provisions in the child-specific conventions, the OPSC and the Lanzarote Convention, lack the level of cybercrime expertise and are too "old school" to cater for the specific circumstances of cybercrime investigations and the volatile nature of digital evidence. And 
in return, the Budapest Convention treats cybercrime broadly as an area of crime which does not typically produce vulnerable witnesses, which can be demonstrated by the lack of any victim-centered procedural provision in the entire Convention. As a result, international cooperation under OPSC and Lanzarote Convention might be less efficient, but more child friendly, while international collaboration in the Budapest Convention might be more efficient, but less child friendly.

It is argued that this is a typical symptom of the academic and practical divide in the field of online child sexual abuse: either, the focus lies on the "child sexual abuse", or on the "online" component. In the former, child protection takes center-stage, while in the latter it is cybercrime issues. This division is partly due to the fact that in-depth discussions of transnational law enforcement mechanisms lie way outside the focus and comfort zone of child rights advocates. Given this obvious gap in adequately responding to online child sexual abuse offences, there is an urgent need to marry child protection with cybercrime expertise, to create standards and instruments which are efficient in the cyber context, while always putting the best interests of the child victim first. This is a task which is yet to be achieved at an international level.

\section{Acknowledgement}

The views expressed in this study are solely those of the author, and not necessarily those of UNICEF.

\section{References}

Amnesty International, Universal Jurisdiction - A preliminary survey of legislation around the world. 2012 Update (London, 2012).

Baldridge, Stephen, "Family Stability and Childhood Behavioral Outcomes: A Critical Review of the Literature", Journal of Family Strengths 2011 (11).

Brenner, Susan W., Cybercrime and the Law: Challenges, Issues, and Outcomes (Boston, 2012).

Brenner, Susan W. and Koops, Bert-Jaap, "Approaches to Cybercrime Jurisdiction", Journal of High Technology Law 2004 (4).

Broadhurst, Roderic, "Developments in the global law enforcement of cyber-crime, Policing" in International Journal of Police Strategies and Management, 2006 (29).

Council of Europe, Explanatory Report to the Convention on Cybercrime, European Treaty Series, No. 185 (Budapest, 2001). 
Council of Europe, Convention on the Protection of Children against Sexual Exploitation and Sexual Abuse - Explanatory Report (2007).

Council of Europe, Terms of Reference for the Preparation of a Draft 2nd Additional Protocol to the Budapest Convention on Cybercrime (Strasbourg, 2017).

CRC Committee, Guidelines regarding the implementation of the Optional Protocol to the Convention on the Rights of the Child on the sale of children, child prostitution and child pornography (CRC/C/156, 2019).

CRC Committee, General Comment No. 14 on the right of the child to have his or her best interests taken as a primary consideration (CRC/C/GC/14, 2013).

CRC Committee, General Comment No. 25 on children's rights in relation to the digital environment (CRC/C/GC/25, 2021).

ECPAT, Trends in online child sexual abuse material Bangkok (2018), 29.

ECPAT and University of Bedfordshire, Connecting the Dots: Supporting the Recovery and Reintegration of Children Affected by Sexual Exploitation (Bangkok, 2017).

Geoff Gilbert, Responding to International Crime (Leiden, 20o6).

Gewirtz-Meydana, Ateret, Walsha, Wendy, Wolaka, Janis and Finkelhora, David, "The complex experience of child pornography survivors", Child Abuse and Neglect 2018 (8o).

Ghimire, Devika and Follette, Victoria M., "Revictimisation - Experiences related to Child, Adolescent and Adult Sexual Trauma" in Melanie P. Duckworth and Victoria M. Follette Retraumatization: Assessment, Treatment, and Prevention (New York, 2012).

Gillespie, Alisdair A., Child Pornography. Law and Policy (New York:RoutledgeCavendish, 2011).

Gillespie, Alisdair, "Jurisdiction issues concern online child pornography”, International Journal of Law and Information Technology 2012 (92).

Government of Austria, Austrian comments on the DRAFT Guidelines on the implementation of the Optional Protocol to the Convention on the Rights of the Child on the sale of children, child prostitution and child pornography (2019).

Government of Japan, Japan's Comments on the Draft Guidelines on the implementation of the Optional Protocol to the Convention on the Rights of the Child on the sale of children, child prostitution and child pornography (2019).

Hunter, Sally, Childhood Sexual Experiences: Narratives of Resilience (Oxford: New York, 2010).

Ireland-Piper, Danielle, Extraterritorial Criminal Jurisdiction: Does the Long Arm of the Law Undermine the Rule of Law, Melbourne Journal of International Law, Vol. 13 (2012).

Kolossa, Stephan, "The charm of jurisdictions: a modern version of Solomon's judgement?", Voelkerrechtsblog, 5 June 2019: https://voelkerrechtsblog.org/ 
the-charm-of-jurisdictions-a-modern-version-of-solomons-judgment/. Accessed 1 August 2019.

Lee-Makiyama, Hosuk, A Multilateral Legal Assistance Protocol: Preventing Fragmentation and Re-territorialisation of the Internet, ECIPE Policy Briefs No. 9/2013.

Maillart, Jean-Baptiste, The limits of subjective territorial jurisdiction in the context of cybercrime, ERA Forum (2019).

Miquelon-Weismann, Miriam F., "The Convention on Cybercrime: A Harmonized Implementation of International Penal Law: What Prospects for Procedural Due Process?", Journal for Computer \& Information Law 2005 (32).

Oerlemans, Jan-Jaap, Investigating cybercrime (Amsterdam, 2017).

Osula, Anna-Maria, "Mutual Legal Assistance \& Other Mechanisms for Accessing Extraterritorially Located Data", Masaryk University Journal of Law and Technology, 2015 (9).

Osula, Anna-Maria, "Transborder access and territorial sovereignty", Computer Law and Security Review, 2015 (32).

Pullen, Philip J., "Nail in the MLAT Coffin: Examining Alternatives Solutions to the Current Mutual Legal Assistance Treaty Regime in International Cross-Border Data Sharing", North Carolina Journal of International Law 2018 (44).

Ryngaert, Cedric, The Concept of Jurisdiction in International Law in Alexander Orakhelashvili, Research Handbook on Jurisdiction and Immunities in International Law (Cheltenham, 2015).

Skelton, Ann and Mezmur, Benyam, “Technology changing @ a Dizzying Pace: Reflections on selected jurisprudence of the UN Committee on the Rights of the Child and Technology", Peace Human Rights Governance 2019 (3).

Svantesson, Dan and Gerry, Felicity, "Access to extraterritorial evidence: The Microsoft cloud case and beyond", Computer Law and Security Review (2015 (31).

UN Economic and Social Council, Guidelines on justice in matters involving childvictims and witnesses of crime, E/CN.15/2005/L.2/Rev.1 (2005).

UN General Assembly, Declaration of Basic Principles of Justice for Victims of Crime and Abuse of Power, E/AC.57/1990/3.

UNICE F Innocenti, Handbook on the Optional Protocol on the Sale of Children, Child Prostitution and Child Pornography (Florence, 2009).

UNICE F, Regulation of Child Online Sexual Abuse. Legal Analysis of International Law \& Comparative Legal Analysis (Windhoek, 2016).

UNICEF, State of the World's Children (New York, 2017).

UNICEF, The Child Witness: A Training Manual (Windhoek, 2019).

UNODC, Manual on Mutual Legal Assistance and Extradition (New York, 2012). UNODC, Comprehensive Study on Cybercrime Draft - February 2013 (New York, 2013). 
UNODC, Study on the Effects of New Information Technologies on the Abuse of Children (New York, 2015).

UnOdc/Unicef, Handbook for Professionals and Policymakers on Justice Matters involving Child Victims and Witnesses of Crime (New York, 2005).

Unodc/Unicef, Training Programme on the Treatment of Child Victims and Child Witnesses of Crime for Prosecutors and Judges (New York, 2015).

Weber, Amalie M., "The Council of Europe's Convention on Cybercrime", Berkeley Technology Law Journal 2003 (18).

Witting, Sabine K., “The 'Greyscale' of 'Child Pornography': Of Mangas, Avatars and School Girls: Part 1”, Computer and Telecommunications Law Review 2018 (3).

Witting, Sabine K., “The 'Greyscale' of 'Child Pornography': Of Mangas, Avatars and School Girls: Part 2", Computer and Telecommunications Law Review 2018 (4).

Witting, Sabine K., "Regulating bodies - the moral panic of child sexuality in the digital era", Critical Quarterly for Legislation and Law (2019 (1).

Witting, Sabine K., Child Sexual Abuse in the Digital Era - Rethinking Legal Frameworks and Transnational Law Enforcement Collaboration (University of Leiden, 2020). 